\title{
Semaphorin3A Inhibits Nerve Growth Factor-Induced Sprouting of Nociceptive Afferents in Adult Rat Spinal Cord
}

\author{
Xiao-Qing Tang, ${ }^{1}$ Darrell L. Tanelian, ${ }^{2}$ and George M. Smith ${ }^{1}$ \\ ${ }^{1}$ Department of Physiology, Spinal Cord and Brain Injury Research Center, University of Kentucky Chandler Medical Center, Lexington, Kentucky 40536- \\ 0298, and ${ }^{2}$ Medical City Dallas Hospital, Dallas, Texas 75230
}

\begin{abstract}
Increased expression of NGF after spinal cord injury induces sprouting of primary nociceptive axons. Exogenous application of NGF also results in extensive sprouting of these axons and causes chronic pain in uninjured animals. During development, semaphorin $3 \mathrm{~A}$ is thought to act as a repulsive guidance cue for NGF-responsive nociceptive afferents, restricting their projections to the superficial dorsal horn. We investigated the ability of semaphorin $3 \mathrm{~A}$ to selectively reduce NGF-induced sprouting and neuropathic pain in adult rats. The chemorepulsive effect of virus-mediated semaphorin3A expression was shown to counteract the sprouting induced by NGF in a dosedependent manner, both in vitro and in adult rat spinal cords. Coexpression of semaphorin3A and NGF at moderate to low concentrations within the adult spinal cord reduced sprouting of calcitonin gene-related peptide and substance P-containing axons compared with GFP and NGF coexpression controls. At high expression levels of NGF, there was no difference in sprouting between the semaphorin3A-treated and control groups. The distribution of endogenous primary nociceptive afferents in the spinal cord appeared to be unaffected by semaphorin3A treatment in these experiments. Behavioral assessment shows that semaphorin3A coexpression with NGF led to decreased mechanical allodynia but no significant reductions in thermal hyperalgesia. These findings demonstrate directly that mature sensory afferents maintain their responsiveness to semaphorin $3 \mathrm{~A}$, suggesting that this molecule might be used therapeutically to control aberrant sensory sprouting involved in pain or autonomic dysfunction.
\end{abstract}

Key words: semaphorin3A; nerve growth factor; nociceptive afferents; sprouting; gene therapy; spinal cord; pain

\section{Introduction}

NGF action on either peripheral or central nerve terminals greatly exacerbates primary sensory nociception. Injury to the spinal cord results in an increased expression of NGF (Nakamura and Bregman, 2001), which acts to increase both neuropeptide expression and sprouting of nociceptive axons (Christensen and Hulsebosch, 1997; Gwak et al., 2003). The relative contribution by each of these potential mechanisms to the type and severity of pain is not known. Several studies demonstrate that administration of antibodies directed against NGF or TrkA-IgG chimera greatly reduce NGF-induced pain responses and also reduce both sprouting and neuropeptide expression (McMahon et al., 1995; Christensen and Hulsebosch, 1997; Gwak et al., 2003). To better understand the components of pain contributed by spouting of nociceptive afferents, we have used semaphorin $3 \mathrm{~A}$ (Sema3A) to control NGF-induced spouting independent of other NGFmediated events within the noninjured spinal cord.

Previously, we showed that injection of adenovirus encoding NGF (NGF/Ad) into the adult dorsal spinal cord induced robust

Received April 28, 2003; revised Nov. 11, 2003; accepted Nov. 25, 2003.

This work was supported by National Institute of Neurological Disorders and Stroke Grant NS 38126 . We thank Melody King, Raymond Collins, and Lorna Putnam for histological assistance; Udesh DeSilva for quantification of outgrowth; and Dr. Diane M. Snow and Jeffrey D. Smith for providing fertilized chick eggs.

Correspondence should be addressed to Dr. George M. Smith, Department of Physiology, MS 508, Spinal Cord and Brain Injury Research Center, University of Kentucky Chandler Medical Center, Lexington, KY 40536-0298. E-mail: gmsmith@uky.edu.

DOI: 10.1523/JNEUROSCI.1263-03.2004

Copyright $\odot 2004$ Society for Neuroscience $\quad$ 0270-6474/04/240819-09\$15.00/0 sprouting of sensory afferents throughout the entire dorsal horn, ventral horn, and the white matter of the lateral funiculus (Romero et al., 2000). Ectopic distribution of these afferents led to hyperalgesia and chronic pain in normal, unlesioned rats. Because during development Sema3A is thought to restrict sensory axon projections (Messersmith et al., 1995), we constructed an adenovirus encoding Sema3A and investigated whether it could function in the adult spinal cord to reduce NGF-induced sprouting and, thus, prevent the aberrant innervation that contributes to abnormal pain.

Semaphorins are a family of secreted and membraneanchored glycoproteins important in repulsive axon guidance during neuroembryogenesis (Yu and Kolodkin, 1999). Sema3A, one of the best characterized members in this family, is a diffusible molecule that induces growth cone collapse and axon repulsion of several neuronal populations ( $\mathrm{He}$ and Tessier-Lavigne, 1997; Kolodkin et al., 1997; Takahashi et al., 1999; Tamagnone et al., 1999), through interaction with a neuropilin-1/plexin-A1 receptor complex. One of its roles during development is the establishment of an appropriate pattern of innervation within the dorsal horn of the spinal cord (Luo et al., 1993; Messersmith et al., 1995; Behar et al., 1996; Puschel et al., 1996; Shepherd et al., 1997; Pasterkamp et al., 2000). Sema3A acts to selectively repel axons from a subset of embryonic dorsal root ganglion (DRG) neurons that are of small diameter, NGF responsive, and involved in thermoreception and nociception. Expression of Sema3A in the embryonic ventral horn is thought to restrict the growth of these 
axons to laminas I and II of the dorsal horn. The first demonstration that adult neurons retain the ability to respond to Sema3A was shown by in vivo expression of Sema3A in adult corneal epithelium, resulting in the repulsion of peripheral trigeminal thermoreceptors and nociceptors from the Sema3A-expressing regions (Tanelian et al., 1997). More recently, small diameter neurons within the adult DRG have been shown to retain their expression of neuropilin-1/plexin A1 receptors (Reza et al., 1999; Gavazzi et al., 2000). Yet, direct demonstration for in vivo responsiveness to Sema3A by adult DRG neurons is absent.

\section{Materials and Methods}

Construction of adenoviral vectors. Replication-defective Sema3Aexpressing adenovirus (Sema3A/Ad) was constructed as described by $\mathrm{He}$ et al. (1998). The coding region of Sema3A with a Myc-epitope tag (a gift from Dr. Corey S. Goodman, University of California at Berkeley, Berkeley, CA) was inserted into the pAdtrack-GFP vector. Recombinant adenovirus was generated using the AdEasy system (He et al., 1998), in which the vector was modified to include a temperature-sensitive mutation (ts125) within the DNA-binding protein of adenovirus (Romero and Smith, 1998). After transfection of 293 cells, virus production was monitored by green fluorescent protein (GFP) expression and plaque formation. Adenovirus was amplified and purified on a cesium-chloride gradient as described (Romero and Smith, 1998). The viral particle to pfu ratio is $\sim 5: 1$.

Explant coculture and repulsion assay. An astrocytoma cell line (U373) was transfected/cotransfected with GFP/Ad, NGF/Ad, and Sema3A/Ad for $8 \mathrm{hr}$ at $37^{\circ} \mathrm{C}$. The next day, cells were harvested, aggregated, and embedded in collagen gels with embryonic day (E) 10 chicken DRG at a distance of $700-1000 \mu \mathrm{m}$, essentially as described by Messersmith et al. (1995). Explants were cultured in DMEM/N2 medium containing 0.5\% FBS and $50 \mathrm{ng} / \mathrm{ml} \beta$-NGF (Invitrogen, Grand Island, NY). Forty-eight hours later, cultures were fixed with $4 \%$ paraformaldehyde and stained with crystal violet. Digital images were taken, and the angle between the borders of DRG neurite outgrowth (as diagrammed in Fig. 1C) was measured to quantify the repulsive/attractive influence from the aggregates. Reduction in the degrees of overall neurite growth is reflective of greater chemorepulsion.

Spinal surgery and adenovirus administration. Forty-six adult (250$300 \mathrm{gm}$ ) Sprague Dawley rats (Harlan Sprague Dawley, Indianapolis, IN) were used in this study. Spinal cord microinjection was performed as described previously (Romero and Smith, 1998; Romero et al., 2000). Briefly, rats were anesthetized and underwent hemilaminectomies at the T13-L1 vertebral segments. As described previously, animals received $100 \mu \mathrm{g}$ intraperitoneally of a combined solution of rat CD-4 (W3/25) and CD-45 (MRC OX-22) antisera for transient immune suppression. Each animal received eight injections $(0.3 \mu \mathrm{l} ; 0.5 \mathrm{~mm}$ apart and $1.1 \mathrm{~mm}$ deep) of individual or combined viral vectors along the L4-L5 dorsal root entry zone. All injections were made using a glass micropippette pulled to an external diameter of $50 \mu \mathrm{m}$ and beveled so that multiple injections could be made along the entry zone with minimal damage to the cord. The injection depth and location was controlled using a micromanipulator. To remove variation in depth attributable to breathing, the rat was suspended using a spinal harness. A nanoliter injection device (World Precision Instruments, Sarasota, FL) was used to inject a very small, but precise, volume of virus. At each injection site, $0.3 \mu \mathrm{l}$ of a saline solution containing GFP/Ad $\left(1.25 \times 10^{6} \mathrm{pfu} / \mu \mathrm{l}\right)$, Sema3A/Ad $(1.25 \times$ $\left.10^{6} \mathrm{pfu} / \mu \mathrm{l}\right)$, or a mixture of GFP/Ad and NGF/Ad or Sema3A/Ad and NGF/Ad at ratios of 1:0.04 $\left(1.25 \times 10^{6}\right.$ and $\left.5.0 \times 10^{4} \mathrm{pfu} / \mu \mathrm{l}\right), 1: 0.1$ $\left(1.25 \times 10^{6}\right.$ and $\left.1.25 \times 10^{5} \mathrm{pfu} / \mu \mathrm{l}\right), 1: 0.2\left(1.25 \times 10^{6}\right.$ and $2.5 \times 10^{5}$ $\mathrm{pfu} / \mu \mathrm{l})$, or $1: 1\left(1.25 \times 10^{6}\right.$ and $\left.1.25 \times 10^{6} \mathrm{pfu} / \mu \mathrm{l}\right)$ was slowly infused $(5$ $\mathrm{nl} / \mathrm{sec}$ ) into the cord. After each injection, the micropipette was left in place for $1 \mathrm{~min}$ before being withdrawn from the spinal cord. Our previous studies demonstrated that this procedure resulted in robust transgene expression distributed consistently throughout the injected area, with little cell death or tissue damage. The adenovirus-mediated transgene expression was primarily localized to astrocytes in the dorsal horn and motor neurons within the ventral horn on the injected side of the
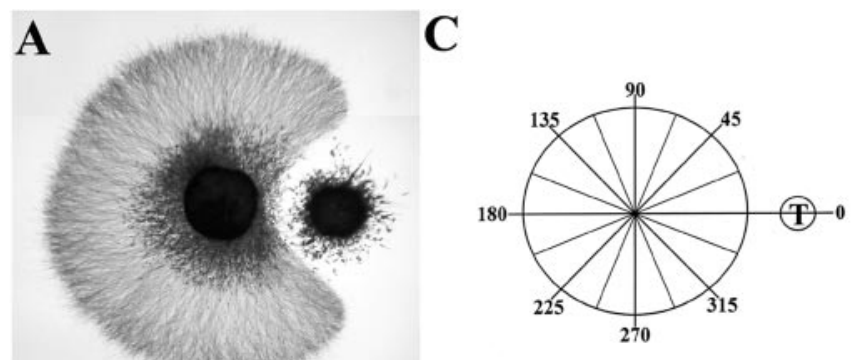

\section{GFP/Ad}

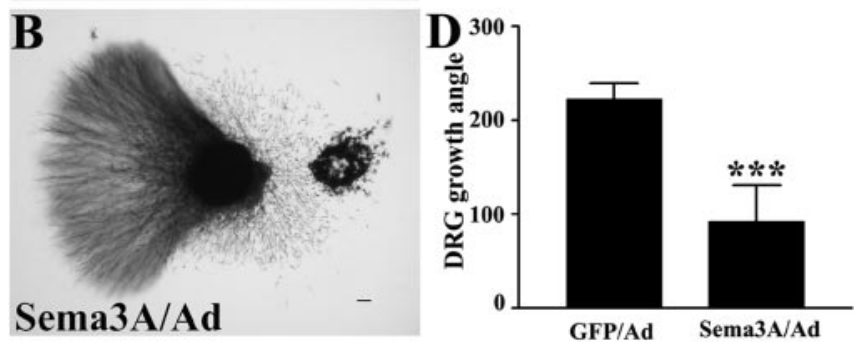

Figure 1. Functional analysis of Sema3A/Ad. U373 cells were transfected with 30 pfu/cell GFP control virus or virus encoding Sema3A. GFP/Ad-transfected U373 cell aggregates shows a contact-mediated inhibition on axonal growth from E10 chicken DRG in medium containing $\operatorname{NGF}(A)$, whereas Sema3A/Ad-transfected aggregates display a much stronger chemorepulsive effect on axonal growth $(B)$. Schematic representation of the method used to quantify the total circumferential degrees of DRG axonal growth in relationship to transfected cells (C).D, Axon growth angle of DRG cultured with aggregates secreting Sema $3 A$ is significantly smaller $(92.5 \pm 38 ; n=16)$ compared with GFP control aggregates $(222.5 \pm 17 ; n=6)$. Values represent mean \pm SD of at least three independent experiments. ${ }^{* *} p<0.001$, analyzed by unpaired $t$ test. Scale bar, $100 \mu \mathrm{m}$.

spinal cord, peaking between 7 and $14 \mathrm{~d}$ after virus administration (Romero and Smith, 1998; Romero et al., 2000). After injections, dorsal musculature was sutured, and the skin incision was closed. All surgery and animal care was done following the Institutional Animal Care and Research Advisory Committee regulations.

Behavioral analysis. Tactile hyperalgesia was evaluated by measuring the nociceptive response to a cutaneous mechanical stimulus, as described by Chaplan et al. (1994). Briefly, rats were placed in a clear plastic chamber on a wire mesh floor. After a habituation period, a series of eight von Frey hairs $(0.41,0.70,1.20,2.00,3.63,5.50,8.50$, and $15.10 \mathrm{gm}$; North Coast Medical, Morgan Hill, CA) were applied to the mid-plantar area of the hindpaws following an up-and-down profile (Dixon, 1980; Chaplan et al., 1994). Stimuli for each paw were presented for $\sim 6-8 \mathrm{sec}$ at intervals of several seconds. The total number of stimuli applied to each paw ranges from five to nine, depending on different response pattern. The $50 \%$ withdrawal threshold was calculated to represent the force causing $50 \%$ likelihood of withdrawal response. A minimum of four up-and-down trials was performed to identify the $50 \%$ withdrawal threshold. Behavioral response to noxious thermal stimuli was measured according to methods described previously (Romero et al., 2000, 2001). Individuals conducting these experiments were always blinded as to the treatment. All animals were tested before adenoviral injection to establish baselines and then 1 week, and 2 weeks after the injection.

Western blot of NGF and Sema3A. In vitro and in vivo expression of NGF and Sema3A was evaluated as described previously (Tanelian et al., 1997; Romero et al., 2000). The in vitro expression of NGF and Sema3A was evaluated $48 \mathrm{hr}$ after virus infection of U373 cells. One milliliter of culture supernatant was precipitated by 0.1 volume of $0.5 \%$ sodium deoxycholate and 0.1 volume of TCA. Proteins were pelleted by centrifugation at $14,000 \mathrm{rpm}$, washed in $80 \%$ acetone, dried, and resuspended in $100 \mu \mathrm{l}$ of Laemmli's buffer. Twenty microliters of each sample were loaded for the Western blot. For in vivo expression of Sema3A/Ad, rats were anesthetized deeply $8-10 \mathrm{~d}$ after virus injection. A $6 \mathrm{~mm}$ segment of the ipsilateral spinal cord containing the L4- and L5-injected regions was dissected and immediately frozen. The tissue was then homogenized 
manually with a dounce in $200 \mu \mathrm{l}$ of $1 \%$ SDS in Tris-EDTA buffer with proteinase inhibitors ( $10 \mu \mathrm{g} / \mathrm{ml}$ aprotinin, $1 \mu \mathrm{g} / \mathrm{ml}$ leupeptin, and $1 \mathrm{~mm}$ PMSF) and sonicated using a Branson sonifier 450 (VWR Scientific, West Chester, PA). After centrifuging at 14,000 rpm, supernatant was assayed for protein concentration using a BCA kit (Pierce, Rockford, IL), diluted with $3 \times$ Laemmli's buffer, and $50 \mu \mathrm{g}$ of protein was loaded for each sample. After running the sample in either 14\% (for NGF) or $10 \%$ (for Sema3A) SDS-polyacrylamide gel, proteins were transferred to polyvinylidene difluoride membranes. Membranes were blocked using $5 \%$ nonfat dry milk in TBS with $0.05 \%$ Tween 20 (TBST). NGF was identified by rabbit anti-NGF antibody (1:500; Accurate, Westbury, NY), and adenovirus-mediated Sema3A expression was detected by mouse anti-Myc 9E10 antibody (1:1000; Developmental Hybrodoma Bank, Iowa City, IA). After a $3 \mathrm{hr}$ incubation in primary antibody, the membranes were washed five times, $10 \mathrm{~min}$ in TBST, and incubated in goat anti-rabbit (for NGF) or mouse (for Sema3A) IgG (1:7500; Promega, Madison, WI) conjugated with alkaline phosphatase for $1 \mathrm{hr}$. Membranes were washed as above and developed using 5-bromo-4-chloro-3indolyl phosphate/nitro blue tetrazolium solutions (Boehringer Mannheim, Indianapolis, IN).

NGF ELISA for spinal cord samples. For animals injected with various concentrations of NGF/Ad, the spinal cords were isolated and frozen as for Western analysis. The tissues were further processed according to the manufacturer's instructions (Promega), with the additional step of pretreating each sample using G-protein agarose to absorb the rodent IgGs. Homogenates were incubated with G-protein agarose (Boehringer Mannheim) overnight at $4^{\circ} \mathrm{C}$ while shaking. Protein assays were performed, and 100 and $10 \mu \mathrm{g} / \mathrm{ml}$ (100 $\mu \mathrm{l} /$ well $)$ of each sample was used for the assay. After development, 96-well plates were read at $450 \mathrm{~nm}$ using a BioTech E12a microplate reader.

$B$-subunit of cholera toxin tract tracing. Fourteen days after injection of NGF/Ad into the right side of the spinal cord, a solution of B-subunit of cholera toxin (CTB; List Biological Laboratories, Campbell, CA) was injected into the sciatic nerve. This was done bilaterally using a glass micropipette to inject $2 \mu \mathrm{l}$ of a $1 \%$ solution of CTB into each side. Four days after injection, animals were perfused using $4 \%$ paraformaldehyde and processed for cryosectioning. Sections were double-labeled for CTB and calcitonin gene-related peptide (CGRP) to examine whether any of the CGRP-positive axons colabeled with CTB. To identify CTB-labeled axons, sections were stained using goat anti-CTB (1:1000; List Biological Laboratories), followed by CGRP staining. Visualization was achieved by tissue incubation in either fluorescent or biotinylated secondary antibodies. Biotin-labeled tissue was further processed using the Vectastain Elite $\mathrm{ABC}$ reagents (Vector Laboratories, Burlingame, $\mathrm{CA}$ ) and developed using two peroxidase substrate kits for brown and blue color (Vector SG). All images were captured using a coolsnap cf. video camera connected to E-800 epifluorescent microscope (Nikon).

Isolectin B4 binding and CGRP immunofluorescence. Cryosections were incubated simultaneously in rabbit anti-CGRP (1:500; Sigma, St. Louis, MO) and biotinylated isolectin B4 (IB4) lectin (1:100; Sigma). Visualization was achieved by incubation in Texas Red-labeled goat anti-rabbit (1:200; Jackson ImmunoResearch, West Grove, PA) and FITC-labeled streptavidin (1:500; Jackson ImmunoResearch). Sections were mounted on slides and coverslipped with 5\% propyl-gallate in glycerol for fluorescence microscopy.

Immunocytochemistry and image analysis. All staining and image analyses were done following methods described previously (Romero et al., $2000,2001)$. At the end of the study, animals were perfused transcardially with $0.9 \%$ saline, followed by $4 \%$ paraformaldehyde in $0.1 \mathrm{~m}$ phosphate buffer, $\mathrm{pH}$ 7.5. After perfusion, the lumbar spinal cord was removed and postfixed before it was transferred to a $30 \%$ sucrose solution for cryoprotection. Thirty-micrometer-thick tissue sections were cut on a cryostat and divided into five alternate sets. The tissue sections were used either immediately for histological analysis or stored in cryoprotectant solution at $-20^{\circ} \mathrm{C}$ until processed. For immunohistochemistry, floating tissue sections were incubated in polyclonal antiserum against rat CGRP (1: 20,000; Sigma) or substance-P (1:10,000; Sigma-RBI, Natick, MA). After visualization using biotinylated secondary antibodies, axonal growth was quantified using MetaMorph Image Analysis software (Universal Imag- ing, West Chester, PA). Images from two randomly selected regions within the L4 and L5 segments per animal were quantified by first applying a standardized optical density threshold, followed by measuring the area, in square micrometers, occupied by density profiles equal to or greater than the threshold. For each section, the measurements were taken from the dorsal horn lateral to midline and above the plane of the spinal canal.

Statistical analysis. Raw data from DRG growth angle and image analysis were evaluated using Student's $t$ test or one-way ANOVA, followed by a Tukey-Kramer post hoc test to determine significant differences between treatment. Paw withdrawal latencies (PWLs) to thermal stimuli were analyzed using two-way ANOVA with repeated measures to determine the effects of treatment over time. Fifty percent withdrawal thresholds to mechanical stimuli were compared with nonparametric KruskalWallis or Mann-Whitney $U$ test. Data represent the mean \pm SD. Values below the $5 \%$ probability level were considered significant.

\section{Results \\ Construction and functional characterization of adenoviral vector}

To examine the ability of Sema3A to reduce NGF-induced sprouting within the spinal cord, we generated Sema3A/Ad. To verify biological activity of virus-derived Sema3A, U373 cells were transfected using $30 \mathrm{pfu} /$ cell GFP/Ad (negative control) or Sema3A/Ad. This astrocyte cell line was chosen because of its similar transduction efficiency and cellular properties to primary astrocytes. Aggregates of transfected cells were cocultured with E10 chicken DRG in three-dimensional collagen gels supplemented with NGF to enhance survival of the sensory neurons (Ruit et al., 1992; Zhang et al., 1994). DRG cultured with Sema3A/Ad transfected aggregates demonstrated a strong chemorepulsive response, in which axons grew in a direction opposite to the transfected cell aggregate (Fig. $1 B$ ), whereas DRG cultured with GFP-expressing U373 cells showed a more even, circular growth pattern (Fig. $1 A$ ). Interestingly, in all cultures, axons appeared to avoid direct contact with the U373 cells, suggesting contact-mediated inhibition between these axons and U373 cells. This inhibitory effect was attributed to U373 cells themselves, because a statistically identical growth pattern was observed with untransfected U373 $\left(220 \pm 20^{\circ}\right)$. To quantify the extent of chemorepulsion, the circumferential degree of axonal growth was measured in relationship to the target cell aggregate (Fig. 1C). DRG cultured with GFP/Ad-transfected aggregates displayed a growth angle of $223 \pm 17^{\circ}$, whereas a much smaller axonal growth angle $\left(93 \pm 38^{\circ}\right)$ in a direction opposite to the Sema3A-secreting cells was observed (Fig. 1D).

\section{Sema3A repulsion is regulated by NGF in vitro}

To investigate the extent by which NGF influenced Sema3A chemorepulsion if expressed by a single source, U373 cells were cotransfected with $30 \mathrm{pfu} / \mathrm{cell}$ Sema3A/Ad and different concentrations of NGF/Ad. Western blot confirmed consistent secretion of Sema3A ( $\sim 97.4 \mathrm{kD})$ and dose-dependent increases in NGF $(\sim 14$ $\mathrm{kD}$ ) production with increased NGF virus titers (Fig. $2 \mathrm{~A}$ ). At the highest titer of NGF/Ad (30 pfu/cell), which was equivalent to the Sema3A/Ad titer, similar levels of protein were expressed for Sema3A and NGF. Exact quantification could not be done because of lack of an ELISA assay for Sema3A. Cotransfection of U373 with Sema3A/Ad and NGF/Ad established a competitive gradient that was used to examine axonal growth in the presence of a dose-dependent increase in NGF chemoattraction against a constant expression level of Sema3A. The growth pattern of DRG cultured with aggregates cotransfected with Sema3A and lower titers of NGF/Ad (Fig. 2D-F) appeared to be similar to that with 
aggregates transfected with Sema3A/Ad alone (Fig. 2C). At the highest NGF concentration, Sema3A failed to induce repulsion, resulting in growth patterns that were indistinguishable from GFP controls (Fig. 2G). DRG cocultured with explants treated with NGF/Ad alone showed little to no repulsion (Fig. $2 \mathrm{H}$ ). Measurements of DRG growth angles (Fig. $2 \mathrm{~B}$ ) confirmed the NGF dose-dependent abolishment of Sema3A-induced repulsion $\left(F_{(6,60)}=\right.$ 33.37; $p<0.0001)$.

\section{Sema3A inhibits NGF-induced sprouting of CGRP-positive sensory afferents in adult rat spinal cord in a dose-dependent manner}

Application of NGF within the spinal cord has been shown to induce robust sprouting of CGRP-positive sensory axons (Christensen and Hulsebosch, 1997; Romero et al., 2000, 2001; Gwak et al., 2003); however, the possibility remains that increased CGRP staining could be attributable to a phenotypic switch in neuropeptide expression within a myelinated sensory subpopulation (Neumann et al., 1996). To examine this possibility, sciatic nerves of NGF/Ad-treated animals were injected with $\mathrm{CTB}$, which is transported transganglionically in large- and mediumdiameter myelinated sensory axons. For these experiments, CTB was injected bilaterally and showed equivalent staining between the control and NGF/Ad-injected sides (Fig. 3A, brown staining). The density of CGRP-positive axons on the NGF/ Ad-injected side, however, increased dramatically (Fig. 3A, blue staining). Higher magnification revealed that the CTB and CGRP are localized to separate axonal populations and, at best, only very few axons were labeled for both markers (Fig. $3 B, C$ ). This was further confirmed using immunofluorescence that clearly shows separation of the two axon populations (Fig. $3 D, E$ ). To further confirm that NGF/Ad injections did not alter the distribution of other nociceptive axonal subpopulations, sections were also double-labeled for IB4 and CGRP (Fig. $3 F$ ). IB4 labels a glial cell line-derived neurotrophic factor-responsive subpopulation of nociceptive axons that are localized to the inner region of lamina II. Overexpression of NGF caused no observable change in the sprouting or distribution of these axons (Fig. $3 F$ ). These data demonstrate that overexpression of NGF within the spinal cord directly increase sprouting of CGRP-positive axons without altering neuropeptide expression or sprouting of the other sensory axon subpopulations examined.

To test the hypothesis that Sema3A could inhibit NGFinduced sprouting of nociceptive fibers, Sema3A/Ad with different titers of NGF/Ad were coinjected into the right dorsal horn of adult rat spinal cords. Sema3A and NGF expression was examined $10 \mathrm{~d}$ after unilateral injections of Sema3A/Ad combined with NGF/Ad at titer ratios of 1:0.04, 1:0.1, 1:0.2, or 1:1. Western blot analysis shows Sema3A expression within the spinal cord of animals coinjected with the highest titer of NGF/Ad (Fig. 4A). NGF protein concentrations within spinal cords were determined by
ELISA and reflected a titer-dependent dose-response of NGF expression (Fig. $4 B$ ). All concentrations were well above endogenous levels, which vary between 0.4 and $1.3 \mathrm{ng} / \mathrm{mg}$ spinal cord tissue with this ELISA assay.

CGRP is a specific marker of small-diameter sensory afferents that terminate primarily in laminas I and II of the dorsal spinal cord (Gibson et al., 1984; Chung et al., 1988), and NGF induces robust sprouting of these afferents into deeper dorsal horn laminas (Oudega and Hagg, 1996; Romero et al., 2000, 2001). The extent of CGRP-positive axon sprouting was compared between spinal cords coinjected with either Sema3A/Ad or GFP/Ad and NGF/Ad at either a 1:0.04 or 1:0.2 ratio. These ratios were chosen because, in pilot experiments, no inhibition of NGF-mediated sprouting was observed at equal titers of Sema3A/Ad and NGF/ Ad. In addition, these titer ratios demonstrated effective Sema3A chemorepulsion in vitro. Consistent with our previous study, extensive sprouting of CGRP-positive fibers throughout the ipsilateral spinal cord, including the intermediate zone, ventral horn, and lateral funiculus, was observed 2 weeks after coinjection of GFP/Ad with NGF/Ad at either concentration (Fig. 4D, F). High magnification at the lateral border of the intermediate zone, where very few sensory axons would normally appear, demonstrates the extent of CGRP-positive axonal sprouting (Fig. 4D$G)$. Numerous CGRP-positive axons were also observed growing along blood vessels throughout this region and the dorsal horn. Coinjection of Sema3A/Ad with low concentration of NGF/Ad 

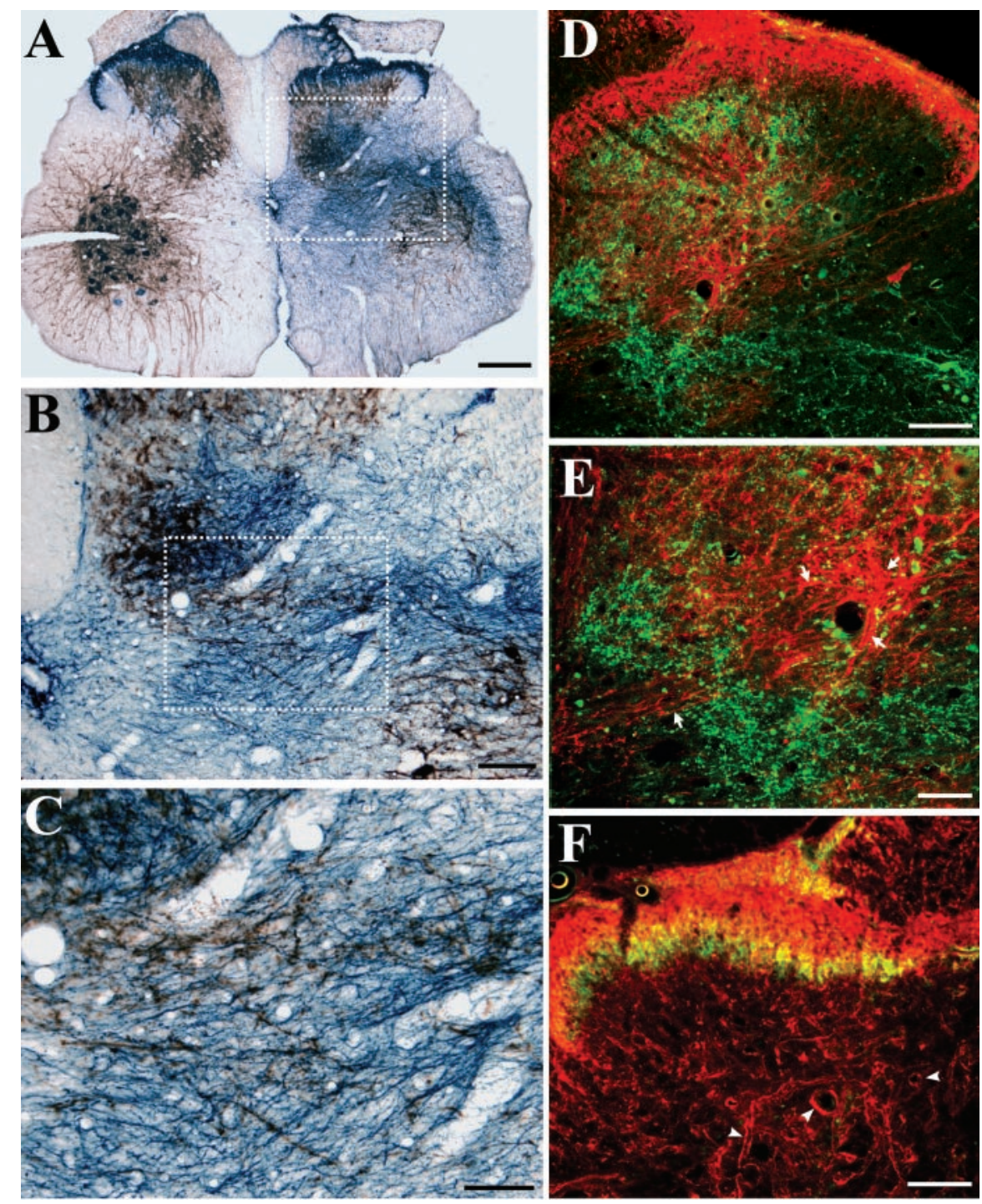

Figure 3. Overexpression of NGF induces robust sprouting of (GRP-positive axons without altering other sensory axons. Fourteen days after NGF/Ad treatment, the ipsilateral CTB staining pattern ( $A-C$, brown axons) for myelinated axons is similar to the contralateral (control side) staining pattern ( $A$ ). The density of (GRP-positive axons (blue) increased dramatically on the NGF/Ad-treated side and extended throughout that spinal cord hemisection. Higher magnifications $(B, C$ reveal very little overlap in staining between the CTB- and CGRP-labeled axons. D, Immunofluorescent staining of CTB ( $g r e e n)$ also shows that very few, if any, of these axons colabel for (GRP (red). Overexpression of NGF induced extensive sprouting of (GRP-positive axons into aberrant spinal cord regions, throughout laminas IV-VI (arrows) and around blood vessels ( $E$, $F$, arrowheads). Nociceptive axons that stain positive for IB4 (green) show no observable sprouting after injection of NGF/Ad into the dorsal spinal cord ( $F$ ). Scale bars: $A, 300 \mu \mathrm{m} ; B, D, F, 100 \mu \mathrm{m} ; C, E, 50 \mu \mathrm{m}$.

(1:0.04) exhibited a greater inhibition on CGRP-positive fibers (Fig. 4G) compared with higher concentrations of NGF/Ad (Fig. $4 E)$. At higher NGF concentrations, CGRP-positive axons sprouted throughout the entire ipsilateral spinal cord, albeit at lower densities (Fig. 4E), even into regions expressing Sema3A, as determined in double-labeled sections (data not shown). To quantify the extent of CGRP fiber sprouting between the treatment groups, the area occupied by these fibers was measured in the right dorsal quadrant of the cord. Sema3A reduced NGFmediated sprouting of CGRP-positive fibers at both concentrations, but statistically significant inhibition $\left(F_{(3,20)}=5.24 ; p<\right.$ 0.01 ) by Sema3A was only achieved at the lower concentration of NGF (Fig. 4C). In the presence of low concentrations of NGF, Sema3A did not appear to affect the density of endogenous
CGRP-positive axons within laminas I and II compared with the contralateral side.

Characterization of the nociceptive fibers inhibited by exogenous Sema3A Our previous studies show that NGF/Ad administration selectively induces neurite sprouting of CGRP and substance P (SP)containing fibers, without affecting the non-peptidergic IB4-positive fibers (Fig. $3 F$ ) (Romero et al., 2000). To further characterize the effect of Sema3A on subgroups of nociceptive afferents, we also examined inhibition of SP-positive fiber sprouting. Consistent with previous experiments, SPpositive fibers extended neurites in response to injection of NGF/Ad $\left(5 \times 10^{4}\right.$ $\mathrm{pfu} / \mu \mathrm{l})$, in a pattern resembling CGRP fiber sprouting, albeit at a much lower fiber density (Fig. 5A,B). Similar to CGRPpositive fibers, no sprouting of SP-positive fibers was observed when Sema3A/Ad was coinjected with NGF/Ad (Fig. 5C,D). Measurements also confirm a significant reduction in the SP fiber-occupying area after Sema3A/Ad injection compared with control (GFP/Ad and NGF/Ad) groups (Fig. 5E).

\section{Sema3A overexpression attenuates the NGF-induced pain responses}

In a previous study, we observed that NGF-induced hyperinnervation of CGRPand SP-positive fibers at the fourth and fifth lumbar segments correlated with the appearance of chronic pain and hyperalgesia (Romero et al., 2000). To identify whether Sema3A chemorepulsion of these nociceptive afferents could reduce NGFmediated pain responses, tests of thermal and mechanical nociception were used. Measurements of PWL to thermal stimuli revealed the appearance of thermal hyperalgesia 2 weeks after coinjection of GFP/Ad and NGF/Ad. With coexpression of Sema3A, a lower level of hyperalgesia was observed (Fig. $6 B$ ), but the difference was not statistically significant $(p<0.1)$. To examine mechanical allodynia, von Frey hairs were used to calculate the 50\% paw withdrawal threshold. Two weeks after coinjection of GFP/Ad and NGF/Ad, a significant decrease in the $50 \%$ withdrawal threshold was observed compared with preinjection or contralateral hindpaw thresholds. Coinjection with Sema3A/Ad, however, significantly increased the threshold toward preinjection or contralateral levels $(p<$ 0.01 ) (Fig. 6D). Another characteristic of chronic pain is a guarding behavior and spontaneous or touch-mediated vocalizations. These behaviors were still observed in Sema3A-treated animals, although the extent of these behaviors seemed reduced. Taken together, these data suggest that Sema3A inhibition of CGRPand SP-positive fiber sprouting is able to reduce some NGFinduced pain responses but fails to fully prevent the progression of neuropathic pain. 


\section{Discussion}

Previously, we demonstrated that Sema3A exerts a repulsive effect on trigeminal sensory nerve terminals innervating the adult rabbit cornea in vivo (Tanelian et al., 1997). However, to date, only indirect evidence exists for a functional role for Sema3A in shaping sensory axon plasticity within the adult spinal cord. NGFresponsive neurons in adult DRG express Sema3A receptor protein neuropilin-1 (Gavazzi et al., 2000) and collapse in response to Sema3A treatment in vitro (Reza et al., 1999). In this study, we demonstrate that Sema3A retains its chemorepulsive effect on NGF-dependent axons within the adult spinal cord in vivo and that this molecule can be used to limit NGF-induced sprouting of nociceptive axons, resulting in a partial reduction in neuropathic pain.

Continual expression of neuropilin-1 by sensory neurons and Sema3A by motor neurons (Pasterkamp et al., 1998) suggest that the receptor functions to restrict sensory afferent plasticity and prevent sprouting in the normal adult spinal cord (Gavazzi, 2001). According to this hypothesis, alterations in signaling, in this case mediated by NGF, that increase the growth response within nerve terminals above the Sema3A chemorepulsive threshold would initiate the formation of a growth cone and, thus, induce growth or sprouting. This would have the overall effect of increasing the size of the terminal branches. The addition of exogenous Sema3A would increase the occupancy of neuropilin-1 receptor complexes and, thus, readjust the signaling threshold within the nerve terminal to induce growth cone collapse and prevent sprouting. Our data support this hypothesis, because Sema3A inhibited sprouting at the lower, more physiological concentrations of NGF examined.

The expression levels for NGF in our experiments ranged from 4 - to 30 -fold above endogenous spinal cord levels. At very high NGF concentrations, Sema3A was incapable of inducing chemorepulsion in vitro or inhibiting axonal sprouting in vivo. Our in vivo data agree with the in vitro observation that neurotrophins modulate Sema3A-mediated growth cone collapse (Song et al., 1998; Tuttle and O'Leary, 1998; Dontchev and Letourneau, 2002). These data are particularly supportive of recent observations by Dontchev and Letourneau (2002), which demonstrated a NGF dose-dependent reduction of growth cone collapse. Strong evidence indicates that neurite growth and growth cone mobility are modulated by the Rho family of small GTPases (Dickson, 2001; Song and Poo, 2001). Activation of TrkA receptors by NGF increases cyclic nucleotides and activates cAMP-dependent protein kinase A (PKA), which is thought to reduce myosin contraction mediated by RhoA GTPase (Cai et al., 1999; Dickson, 2001; Dontchev and Letourneau, 2002). In-
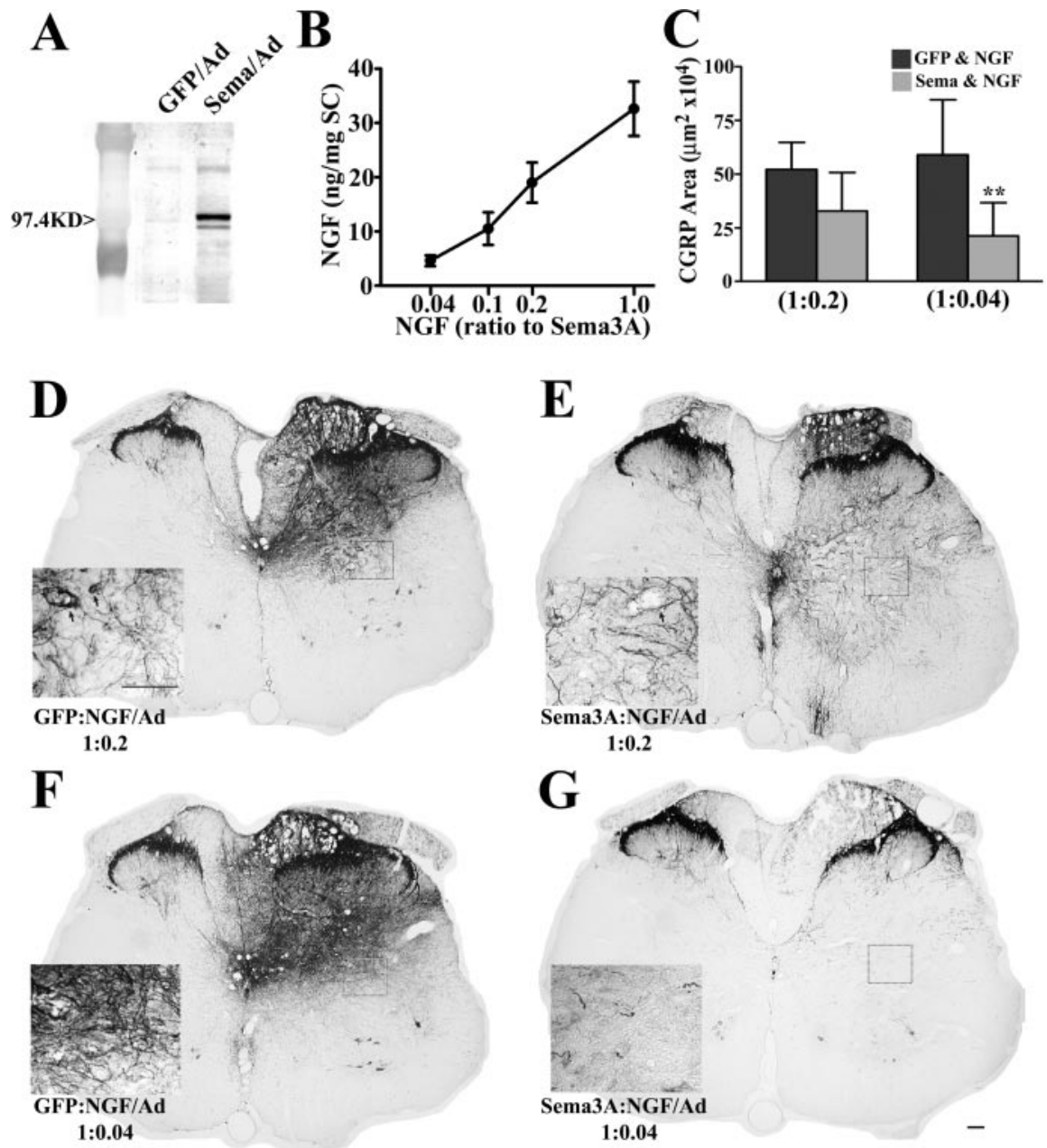

Figure 4. Sema3A inhibits NGF-mediated sprouting of CGRP-positive sensory afferents in adult rat spinal cord. Western blot using 9E10 $\alpha$-Myc monoclonal antibody and NGF ELISA verified Sema3A expression and dose-dependent NGF expression $10 \mathrm{~d}$

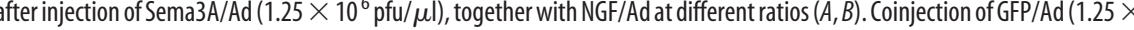
$10^{6} \mathrm{pfu} / \mu \mathrm{l}$ ) and NGF/Ad at either a 1:0.2 or 1:0.04 ratio induced robust sprouting within the ipsilateral, but not contralateral, inal cord $(D, F)$. Coinjection using Sema3A/Ad instead of GFP/Ad shows inhibition of sprouting, which is much greater when sprouting within this region and along blood vessels (arrows). C, Area of (GRP sprouting in the right dorsal quadrant of spinal cords significantly reduced by Sema3A in the presence of lower concentrations of NGF. The means $\pm S D$ for the control and experiThose at the ratio of 1:0.04 for GFP and NGF and Sema3A and NGF are 58.9 \pm 25.7 and 21.2 \pm 15.5 , respectively, with $p=$ 0.002 as determined by a one-way ANOVA, followed by a Tukey post hoc test. Values were calculated from six rats for each treatment. ${ }^{* *} p<0.01$. Scale bar, $100 \mu \mathrm{m}$.

creased levels of cyclic nucleotides within the growth cone prevent collapse and transform the chemorepulsive signal mediated by Sema3A to attraction (Song et al., 1998; Song and Poo, 2001; Dontchev and Letourneau, 2002) and, thus, override Sema3A inhibition of sprouting.

During development, NGF and Sema3A are expressed within the spinal cord and influence pathway guidance of nociceptive axons. Under such circumstances, growth cone guidance is influenced by the coincidental detection of these, and possibly other, signals resulting in the termination of growth within upper dorsal horn. The ability of high concentrations of NGF to reduce the chemorepulsive efficacy of Sema3A might provide a potential mechanism to explain injury-induced sprouting of these axons. Injury to the adult spinal cord induces an upregulation of both NGF and Sema3A; however, these molecules are localized to different compartments. Semaphorin expression is restricted to fi- 

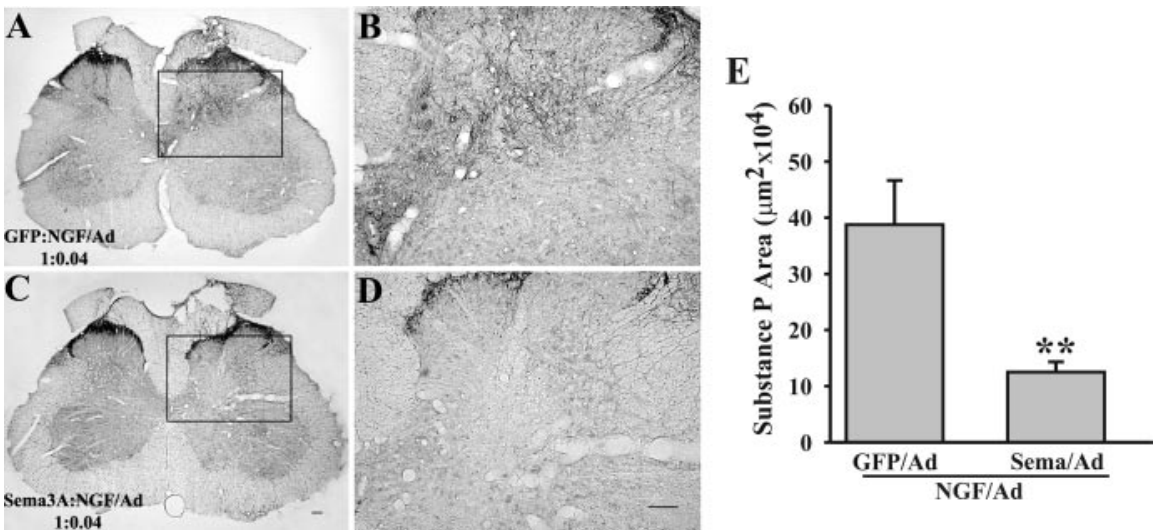

Figure 5. Sema3A inhibits sprouting of SP-containing nociceptive afferents. Two weeks after coinjection of GFP/Ad with NGF/Ad (1:0.04 ratio), robust sprouting of SP-positive fibers within the dorsal spinal cord was apparent $(A, B)$. Coinjection of Sema3A instead of GFP/Ad eliminated aberrant sprouting of SP-positive fibers $(C, D)$. Quantification of SP-containing fiber in the right dorsal horn revealed a significant reduction of fiber growth by Sema3A expression $(E)$. Values represent mean $\pm S D$ of six rats for each group. ${ }^{* *} p<0.01$, analyzed by Student's $t$ test. Scale bar, $100 \mu \mathrm{m}$.
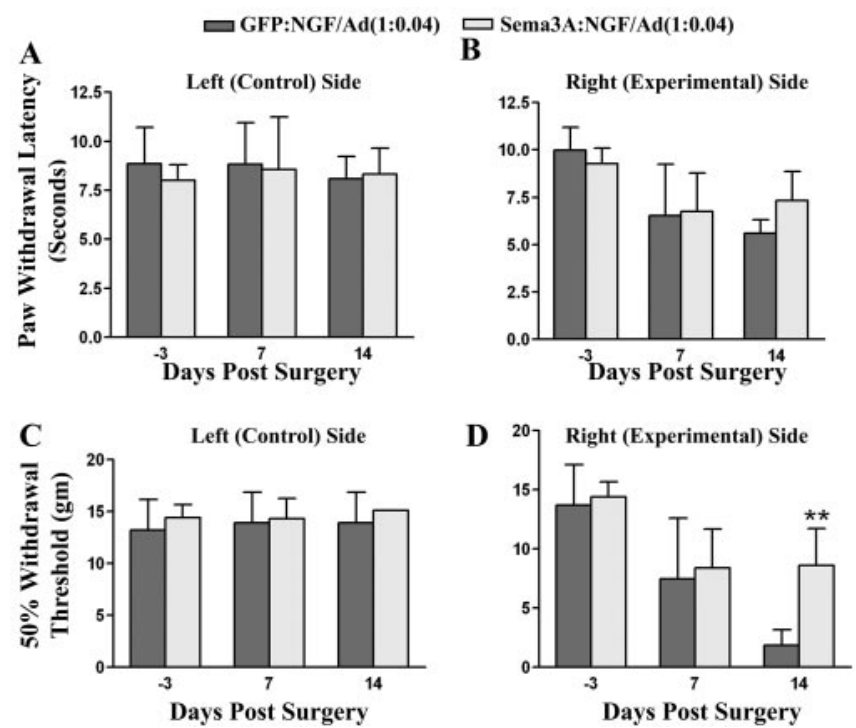

Figure 6. Changes in nociceptive response after treatment. Nociceptive responses were evaluated by measuring the PWL to thermal stimuli $(A, B)$ or the $50 \%$ paw withdrawal threshold to mechanical stimuli $(C, D)$. Measurements were taken from the left (contralateral control) hindpaw $(A, C)$ and the right (experimental) paw $(B, D)$ at $-3,7$, and $14 \mathrm{~d}$ after coinjection of GFP/Ad or Sema3A/Ad $\left(1.25 \times 10^{6} \mathrm{pfu} / \mu \mathrm{l}\right)$ with NGF/Ad at 1:0.04 ratio. The contralateral hind paw demonstrated no thermal hyperalgesia $(A)$ or mechanical allodynia $(C)$ in either treatment group. Sema3A/Ad treatment significantly reversed NGF-mediated reduction of the $50 \%$ withdrawal threshold $14 \mathrm{~d}$ after treatment $(D)$ but not the latency of paw withdrawal. Values represent mean $\pm S D$ of six rats. ${ }^{* *} p<0.01$, analyzed by a nonparametric Mann-Whitney $U$ test.

broblasts within the wound and ventral motor neurons (Pasterkamp et al., 1998, 2001; De Winter et al., 2002), whereas NGF is produced by inflammatory cells and astrocytes throughout and surrounding the lesion site (Krenz and Weaver, 2000; Nakamura and Bregman, 2001). This expression pattern would likely generate higher concentrations of NGF than Sema3A in the dorsal spinal cord and induce axonal sprouting. Several lines of evidence support this mechanism: (1) Sema3A-mediated inhibition of adult nociceptive axon sprouting is dependent on the concentration of NGF in vivo; (2) preconditioning neurons with NGF reduces Sema3A-mediated growth cone collapse in vitro (Dontchev and Letourneau, 2002); (3) NGF increases cyclic nucleotides and activates cAMP-dependent PKA, which reduces myelin and Sema3A-mediated growth cone collapse (Song et al., 1998; Cai et al., 1999; Dontchev and Letourneau, 2002); and (4) anti-NGF treatment reduces sprouting of these axons (Christensen and Hulsebosch, 1997; Krenz and Weaver, 2000). Growth cone behavior and sprouting of adult nociceptive axons are, therefore, modulated by coincident signaling between neurotrophins and semaphorins and depend on a balance between these guidance molecules (Dontchev and Letourneau, 2002). However, at the upper limits of expression of both Sema3A and NGF, our data suggest that NGF-mediated signaling overwhelms Sema3A-mediated repulsion and axon sprouting occurs. The reasons for this effect are unknown but may be attributable to reduced responsiveness to Sema3A because of differences in receptor density on the axon (Owesson et al., 2000), or reduced presence of the cell adhesion molecule L1, which is required for Sema3A/neuropilin-1 signaling (Castellani et al., 2000; Romero et al., 2001). The latter is particularly noteworthy, because we have observed identical inhibition of NGF-induced sprouting by the overexpression of L1 but not neural cell adhesion molecule or N-cadherin (Romero et al., 2001).

\section{Chronic pain and autonomic dysreflexia}

Upregulation of NGF, as seen after peripheral tissue injury, peripheral nerve injury, and spinal cord injury, has been shown to be associated with the development of both acute and chronic pain and can be reversed by administration of anti-NGF antibodies (Woolf et al., 1994; McMahon et al., 1995; Christensen and Hulsebosch, 1997). In the corneal model of peripheral nociception, tissue injury is known to increase NGF (Lambiase et al., 2000), resulting in increased peripheral nerve terminal density and electrophysiological nociceptor responsiveness (Tanelian and Monroe, 1995). In the corneal lesion model, increased Sema3A expression significantly reduced corneal nociceptive axon sprouting and nerve terminal density at endogenous NGF concentrations (Tanelian et al., 1997). Our more recent in vivo studies on spinal cord found upregulation of NGF to induce aberrant sprouting of nociceptive fibers throughout the dorsal horn, accompanied by hyperalgesia and guarding behavior in rats (Romero et al., 2000). Two potential mechanisms by which NGF induces hypersensitivity to pain are by increasing the sprouting of neuropeptide-containing nociceptors and the release of CGRP, SP, or BDNF as neuromodulators of pain (Woolf, 1996; Christensen and Hulsebosch, 1997; Pezet et al., 2002; Gwak et al., 2003). Sema3A-mediated reductions in mechanical allodynia and thermal hyperalgesia are attributed to reductions in the terminal field density associated with sprouting of these nociceptive axons. In our studies, the reversal of hyperalgesia was not complete, suggesting that other mechanisms besides NGF-induced hyperinnervation may participate in the altered pain response. One such possibility is the continual increased production and release of CGRP, SP, or BDNF at normal sites within laminas I and II. NGF has been shown to directly regulate CGRP expression via the cAMP and p42/p44 mitogen-activated protein kinase pathways (Freeland et al., 2000), which have not been shown to be influenced by signaling through the neuropilin-1/plexin re- 
ceptor (Pasterkamp and Kolodkin, 2003). Therefore, semaphorin overexpression should not affect the function of previously established synapses that play a major role in the progression of neuropathic pain. For example, continual expression of neuropeptides or BDNF could act to increase the "gain" of these synapses and reduce the pain threshold (Malcangio et al., 1997; Thompson et al., 1999). Alternatively, rearrangement of non-NGF-responsive terminals may alter central circuits to change innocuous stimulation into noxious sensation (Woolf et al., 1995), which we observed as touch-mediated vocalization in NGF/Sema3A-treated animals.

Another manifestation of increased NGF expression after spinal cord injury is the development of autonomic dysreflexia attributable to aberrant sprouting of NGF-responsive, CGRPimmunoreactive neurons (Jacob et al., 2001; Weaver et al., 2001). Neutralizing intraspinal NGF was able to block autonomic dysreflexia caused by spinal cord injury (Krenz et al., 1999). We are presently examining whether upregulation of Sema3A in the adult spinal cord will be able to prevent or reverse autonomic dysreflexia after spinal cord injury. The findings here lay the groundwork for using Sema3A therapeutically to reduce the aberrant sensory neurite growth that occurs when NGF levels are increased in the adult spinal cord and can lead to acute or chronic pain and autonomic dysreflexia.

\section{References}

Behar O, Golden JA, Mashimo H, Schoen FJ, Fishman MC (1996) Semaphorin III is needed for normal patterning and growth of nerves, bones and heart. Nature 383:525-528.

Cai D, Shen Y, De Bellard M, Tang S, Filbin MT (1999) Prior exposure to neurotrophins blocks inhibition of axonal regeneration by MAG and myelin via a cAMP-dependent mechanism. Neuron 22:89-101.

Castellani V, Chedotal A, Schachner M, Faivre-Sarrailh C, Rougon G (2000) Analysis of the L1-deficient mouse phenotype reveals cross-talk between Sema3A and L1 signaling pathways in axonal guidance. Neuron 27:237-249.

Chaplan SR, Bach FW, Pogrel JW, Chung JM, Yaksh TL (1994) Quantitative assessment of tactile allodynia in the rat paw. J Neurosci Methods 53:55-63.

Christensen MD, Hulsebosch CE (1997) Spinal cord injury and anti-NGF treatment results in changes in CGRP density and distribution in the dorsal horn in the rat. Exp Neurol 147:463-475.

Chung K, Lee WT, Carlton SM (1988) The effects of dorsal rhizotomy and spinal cord isolation on calcitonin gene-related peptide-labeled terminals in the rat lumbar dorsal horn. Neurosci Lett 90:27-32.

De Winter F, Oudega M, Lankhorst AJ, Hamers FP, Blits B, Ruitenberg MJ, Pasterkamp RJ, Gispen WH, Verhaagen J (2002) Injury-induced class 3 semaphorin expression in the rat spinal cord. Exp Neurol 175:61-75.

Dickson BJ (2001) Rho GTPases in growth cone guidance. Curr Opin Neurobiol 11:103-110.

Dixon WJ (1980) Efficient analysis of experimental observations. Annu Rev Pharmacol Toxicol 20:441-462.

Dontchev VD, Letourneau PC (2002) Nerve growth factor and semaphorin $3 \mathrm{~A}$ signaling pathways interact in regulating sensory neuronal growth cone motility. J Neurosci 22:6659-6669.

Freeland K, Liu YZ, Latchman DS (2000) Distinct signalling pathways mediate the cAMP response element (CRE)-dependent activation of the calcitonin gene-related peptide gene promoter by cAMP and nerve growth factor. Biochem J 345:233-238.

Gavazzi I (2001) Semaphorin-neuropilin-1 interactions in plasticity and regeneration of adult neurons. Cell Tissue Res 305:275-284.

Gavazzi I, Stonehouse J, Sandvig A, Reza JN, Appiah-Kubi LS, Keynes R, Cohen J (2000) Peripheral, but not central, axotomy induces neuropilin-1 mRNA expression in adult large diameter primary sensory neurons. J Comp Neurol 423:492-499.

Gibson SJ, Polak JM, Bloom SR, Sabate IM, Mulderry PM, Ghatei MA, McGregor GP, Morrison JF, Kelly JS, Evans RM (1984) Calcitonin generelated peptide immunoreactivity in the spinal cord of man and of eight other species. J Neurosci 4:3101-111.
Gwak YS, Nam TS, Paik KS, Hulsebosch CE, Leem JW (2003) Attenuation of mechanical hyperalgesia following spinal cord injury by administration of antibodies to nerve growth factor in the rat. Neurosci Lett 336:117-120.

He TC, Zhou S, da Costa LT, Yu J, Kinzler KW, Vogelstein B (1998) A simplified system for generating recombinant adenoviruses. Proc Natl Acad Sci USA 95:2509-2514

He Z, Tessier-Lavigne M (1997) Neuropilin is a receptor for the axonal chemorepellent Semaphorin III. Cell 90:739-751.

Jacob JE, Pniak A, Weaver LC, Brown A (2001) Autonomic dysreflexia in a mouse model of spinal cord injury. Neuroscience 108:687-693.

Kolodkin AL, Levengood DV, Rowe EG, Tai YT, Giger RJ, Ginty DD (1997) Neuropilin is a semaphorin III receptor. Cell 90:753-762.

Krenz NR, Weaver LC (2000) Nerve growth factor in glia and inflammatory cells of the injured rat spinal cord. J Neurochem 74:730-739.

Krenz NR, Meakin SO, Krassioukov AV, Weaver LC (1999) Neutralizing intraspinal nerve growth factor blocks autonomic dysreflexia caused by spinal cord injury. J Neurosci 19:7405-7414.

Lambiase A, Manni L, Bonini S, Rama P, Micera A, Aloe L (2000) Nerve growth factor promotes corneal healing: structural, biochemical, and molecular analysis of rat and human corneas. Invest Ophthalmol Vis Sci 41:1063-1069.

Luo Y, Raible D, Raper JA (1993) Collapsin: a protein in brain that induces the collapse and paralysis of neuronal growth cones. Cell 75:217-227.

Malcangio M, Garrett NE, Cruwys S, Tomlinson DR (1997) Nerve growth factor- and neurotrophin-3-induced changes in nociceptive threshold and the release of substance $P$ from the rat isolated spinal cord. J Neurosci 17:8459-8467.

McMahon SB, Bennett DL, Priestley JV, Shelton DL (1995) The biological effects of endogenous nerve growth factor on adult sensory neurons revealed by a trkA-IgG fusion molecule. Nat Med 1:774-780.

Messersmith EK, Leonardo ED, Shatz CJ, Tessier-Lavigne M, Goodman CS, Kolodkin AL (1995) Semaphorin III can function as a selective chemorepellent to pattern sensory projections in the spinal cord. Neuron 14:949-959.

Nakamura M, Bregman BS (2001) Differences in neurotrophic factor gene expression profiles between neonate and adult rat spinal cord after injury. Exp Neurol 169:407-415.

Neumann S, Doubell TP, Leslie T, Woolf CJ (1996) Inflammatory pain hypersensitivity mediated by phenotypic switch in myelinated primary sensory neurons. Nature 384:360-364.

Oudega M, Hagg T (1996) Nerve growth factor promotes regeneration of sensory axons into adult rat spinal cord. Exp Neurol 140:218-229.

Owesson C, Pizzey J, Tonge D (2000) Sensitivity of NGF-responsive dorsal root ganglion neurons to semaphorin $\mathrm{D}$ is maintained in both neonatal and adult mice. Exp Neurol 165:394-398.

Pasterkamp RJ, Kolodkin AL (2003) Semaphorin junction: making tracks toward neural connectivity. Curr Opin Neurobiol 13:79-89.

Pasterkamp RJ, Giger RJ, Verhaagen J (1998) Regulation of semaphorin III/ collapsin-1 gene expression during peripheral nerve regeneration. Exp Neurol 153:313-327.

Pasterkamp RJ, Giger RJ, Baker RE, Hermens WT, Verhaagen J (2000) Ectopic adenoviral vector-directed expression of Sema3A in organotypic spinal cord explants inhibits growth of primary sensory afferents. Dev Biol 220:129-141.

Pasterkamp RJ, Anderson PN, Verhaagen J (2001) Peripheral nerve injury fails to induce growth of lesioned ascending dorsal column axons into spinal cord scar tissue expressing the axon repellent Semaphorin3A. Eur J Neurosci 13:457-471.

Pezet S, Malcangio M, McMahon SB (2002) BDNF: a neuromodulator in nociceptive pathways? Brain Res Rev 40:240-249.

Puschel AW, Adams RH, Betz H (1996) The sensory innervation of the mouse spinal cord may be patterned by differential expression of and differential responsiveness to semaphorins. Mol Cell Neurosci 7:419-431.

Reza JN, Gavazzi I, Cohen J (1999) Neuropilin-1 is expressed on adult mammalian dorsal root ganglion neurons and mediates semaphorin $3 \mathrm{a} /$ collapsin-1-induced growth cone collapse by small diameter sensory afferents. Mol Cell Neurosci 14:317-326.

Romero MI, Smith GM (1998) Adenoviral gene transfer into the normal and injured spinal cord: enhanced transgene stability by combined administration of temperature-sensitive virus and transient immune blockade. Gene Ther 5:1612-1621. 
Romero MI, Rangappa N, Li L, Lightfoot E, Garry MG, Smith GM (2000) Extensive sprouting of sensory afferents and hyperalgesia induced by conditional expression of nerve growth factor in the adult spinal cord. J Neurosci 20:4435-4445.

Romero MI, Rangappa N, Garry MG, Smith GM (2001) Functional regeneration of chronically injured sensory afferents into adult spinal cord after neurotrophin gene therapy. J Neurosci 21:8408-8416.

Ruit KG, Elliott JL, Osborne PA, Yan Q, Snider WD (1992) Selective dependence of mammalian dorsal root ganglion neurons on nerve growth factor during embryonic development. Neuron 8:573-587.

Shepherd IT, Luo Y, Lefcort F, Reichardt LF, Raper JA (1997) A sensory axon repellent secreted from ventral spinal cord explants is neutralized by antibodies raised against collapsin-1. Development 124:1377-1385.

Song H, Poo M (2001) The cell biology of neuronal navigation. Nat Cell Biol 3:E81-E88.

Song H, Ming G, He Z, Lehmann M, McKerracher L, Tessier-Lavigne M, Poo M (1998) Conversion of neuronal growth cone responses from repulsion to attraction by cyclic nucleotides. Science 281:1515-1518.

Takahashi T, Fournier A, Nakamura F, Wang LH, Murakami Y, Kalb RG, Fujisawa H, Strittmatter SM (1999) Plexin-neuropilin-1 complexes form functional semaphorin-3A receptors. Cell 99:59-69.

Tamagnone L, Artigiani S, Chen H, He Z, Ming GI, Song H, Chedotal A, Winberg ML, Goodman CS, Poo M, Tessier-Lavigne M, Comoglio PM (1999) Plexins are a large family of receptors for transmembrane, secreted, and GPI-anchored semaphorins in vertebrates. Cell 99:71-80.

Tanelian DL, Monroe S (1995) Altered thermal responsiviness during regeneration of cold fibers. J Neurophysiol 73:1568-1573.

Tanelian DL, Barry MA, Johnston SA, Le T, Smith GM (1997) Semaphorin
III can repulse and inhibit adult sensory afferents in vivo. Nat Med 3:1398-1401.

Thompson SW, Bennett DL, Kerr BJ, Bradbury EJ, McMahon SB (1999) Brain-derived neurotrophic factor is an endogenous modulator of nociceptive responses in the spinal cord. Proc Natl Acad Sci USA 96:7714-7718.

Tuttle R, O’Leary DD (1998) Neurotrophins rapidly modulate growth cone response to the axon guidance molecule, collapsin-1. Mol Cell Neurosci 11:1-8.

Weaver LC, Verghese P, Bruce JC, Fehlings MG, Krenz NR, Marsh DR (2001) Autonomic dysreflexia and primary afferent sprouting after clipcompression injury of the rat spinal cord. J Neurotrauma 18:1107-1119.

Woolf CJ (1996) Phenotypic modification of primary sensory neurons: the role of nerve growth factor in the production of persistent pain. Philos Trans R Soc Lond B Biol Sci 351:441-448.

Woolf CJ, Safieh-Garabedian B, Ma QP, Crilly P, Winter J (1994) Nerve growth factor contributes to the generation of inflammatory sensory hypersensitivity. Neuroscience 62:327-331.

Woolf CJ, Shortland P, Reynolds M, Ridings J, Doubell T, Coggeshall RE (1995) Reorganization of central terminals of myelinated primary afferents in the rat dorsal horn following peripheral axotomy. J Comp Neurol 360:121-134.

Yu HH, Kolodkin AL (1999) Semaphorin signaling: a little less per-plexin. Neuron 22:11-14.

Zhang L, Schmidt RE, Yan Q, Snider WD (1994) NGF and NT-3 have differing effects on the growth of dorsal root axons in developing mammalian spinal cord. J Neurosci 14:5187-5201. 